LETTER

\section{Diagnostic yield of testing for $R F C 1$ repeat expansions in patients with unexplained adult-onset cerebellar ataxia}

\section{INTRODUCTION}

Cerebellar ataxia, neuropathy, vestibular areflexia syndrome (CANVAS) is an adult-onset, slowly progressive neurodegenerative disorder characterised in its full form by cerebellar ataxia, sensory neuropathy and bilateral vestibulopathy. Autonomic dysfunction and dry cough are also frequent features. CANVAS is usually sporadic, but occasionally occurs in siblings. Recently, a biallelic intronic AAGGG repeat expansion (AAGGG) in RFC1 was identified as the cause in almost all tested familial cases with full CANVAS syndrome. ${ }^{12}$ Interestingly, biallelic (AAGGG) in RFC1 were also found in $22 \%$ of sporadic, previously idiopathic late-onset ataxia cases. ${ }^{1}$ The percentage of positive cases increased to $63 \%$ if only sporadic patients with combined late-onset cerebellar ataxia and sensory neuropathy were considered, and to $92 \%$ in sporadic cases with full CANVAS. ${ }^{1}$ In a cross-sectional description of 100 patients with biallelic RFC1 (AAGGG) all cases had sensory neuropathy on nerve conduction studies (NCS), while only $79 \%$ of cases had cerebellar involvement. ${ }^{3}$ Whether biallelic RFC1 (AAGGG) cause cerebellar ataxia without sensory neuropathy, remains uncertain. Here, we determined the diagnostic yield of testing for RFC1 repeat expansions in a singlecentre cohort of unexplained adult-onset ataxia cases.

\section{PATIENTS AND METHODS}

We included all index patients with ataxia who were evaluated at University Hospitals Leuven in the Movement Disorders Clinic between March 2005 and September 2019 or the Neuromuscular Clinic between January 2000 and December 2018 and fulfilled the following criteria: (1) onset age 18 years or older (onset as early as 19 years has been reported in an RFC1 case) $)^{3}$; (2) ataxia as prominent clinical feature; (3) clinical evidence for cerebellar origin of the ataxia, that is, cerebellar oculomotor disorder (broken pursuit, dysmetric saccades) and/or cerebellar dysarthria; (4) no family history suggesting dominant inheritance; (5) no identified genetic or acquired cause and (6) no rapid progression typical of multiple system atrophy. We performed short-range flanking PCR and repeat-primed PCR for the $(\mathrm{AAAAG})_{\exp }$, (AAAGG) $)_{\exp }$ and (AAGGG)RFC1 alleles on genomic DNA using described primers. ${ }^{1}$

\section{RESULTS}

We included 85 non-related index patients with unexplained adult-onset cerebellar ataxia (onset age: $52 \pm 15.1$ years (mean $\pm S D) ; 41$ female). Nine of the 85 patients had an affected sibling, but these siblings were not included in the current analysis. All 85 probands had previously tested negative for spinocerebellar ataxia (SCA) type 1, 2, 3, 6 and 7. A negative genetic test had been obtained for SCA10, SCA12, SCA17 and dentatorubralpallidoluysian atrophy in 62/85 patients, for Freidreich's ataxia in $61 / 85$ and for Fragile $\mathrm{X}$-associated tremor ataxia syndrome in $37 / 85$.

We identified biallelic (AAGGG) in RFC1 in nine patients (10.6\%; five female; six sporadic). Clinical features are summarised in table 1 .

Onset age was $56 \pm 9.4$ years. At the time of this study, five of nine patients had died (age at death $77 \pm 5.9$ years; mean survival from onset: $20 \pm 5.5$ years).

All nine positive cases had a neuropathy on NCS with predominant or exclusive sensory involvement. In eight of nine cases, this was associated with clinical symptoms and signs of sensory neuropathy. In three cases, NCS also showed motor involvement, although less prominent than the sensory component. Vestibular testing using video-oculography, caloric stimulation and a rotatory chair was performed in three of nine cases. All three had bilateral vestibular hyporeflexia or areflexia and therefore full CANVAS syndrome (two sporadic, one familial). Six of nine cases had autonomic dysfunction and five of nine had chronic cough.

When we restricted our cohort to patients with both cerebellar ataxia and

Table 1 Clinical characteristics of patients with biallelic pathogenic RFC1 expansions

\begin{tabular}{|c|c|c|c|c|c|c|c|c|c|c|c|c|}
\hline $\mathrm{Pt}$ & $\begin{array}{l}\text { Age at } \\
\text { onset } \\
\text { (years), } \\
\text { gender }\end{array}$ & $\begin{array}{l}\text { Age at } \\
\text { examination } \\
\text { (years) }\end{array}$ & $\begin{array}{l}\text { Age at } \\
\text { death } \\
\text { (years) }\end{array}$ & $\begin{array}{l}\text { Cerebellar } \\
\text { atrophy on } \\
\text { MRI }\end{array}$ & $\begin{array}{l}\text { Downbeat } \\
\text { nystagmus }\end{array}$ & $\begin{array}{l}\text { Sensory } \\
\text { symptoms } \\
\text { /signs }\end{array}$ & SNAP & CMAP & $\begin{array}{l}\text { Vestibular } \\
\text { investigation }\end{array}$ & Autonomic & $\begin{array}{l}\text { Chronic } \\
\text { cough }\end{array}$ & Familial \\
\hline 1 & $73, \mathrm{M}$ & 84 & 87 & - & + & + & $\begin{array}{l}\text { UL: } \downarrow / \text { absent } \\
\text { LL: absent }\end{array}$ & $\begin{array}{l}\text { UL: } \downarrow \\
\mathrm{LL}: \downarrow\end{array}$ & NP & U & - & - \\
\hline 2 & $56, F$ & 71 & 75 & + & - & - & $\begin{array}{l}\text { UL: } \downarrow / a b s e n t \\
\text { LL: NP }\end{array}$ & $\begin{array}{l}\mathrm{UL}: \downarrow \\
\mathrm{LL}: \downarrow\end{array}$ & NP & - & + & - \\
\hline 3 & $39, F$ & 46 & - & + & + & + & $\begin{array}{l}\text { UL: } \downarrow / \text { absent } \\
\text { LL: absent }\end{array}$ & $\begin{array}{l}\text { UL: normal } \\
\text { LL: normal }\end{array}$ & $\begin{array}{l}\text { Bilateral } \\
\text { vestibular } \\
\text { hyporeflexia }\end{array}$ & $\mathrm{U}, \mathrm{OH}$ & + & - \\
\hline 4 & $53, M$ & 69 & 79 & + & - & + & $\begin{array}{l}\text { UL: } \downarrow \\
\text { LL: absent }\end{array}$ & $\begin{array}{l}\text { UL: normal } \\
\text { LL: normal }\end{array}$ & NP & - & + & - \\
\hline 5 & 49, M & 59 & 74 & + & - & + & $\begin{array}{l}\text { UL: } \downarrow \\
\text { LL: absent }\end{array}$ & $\begin{array}{l}\text { UL: normal } \\
\text { LL: } \downarrow\end{array}$ & NP & U & - & $\begin{array}{l}\text { Brother with similar } \\
\text { symptoms (NA) }\end{array}$ \\
\hline 6 & $57, F$ & 67 & 72 & - & + & + & $\begin{array}{l}\text { UL: } \downarrow \\
\text { LL: absent }\end{array}$ & $\begin{array}{l}\text { UL: normal } \\
\text { LL: normal }\end{array}$ & NP & U & - & - \\
\hline 7 & $64, F$ & 69 & - & + & + & + & $\begin{array}{l}\text { UL: } \downarrow \\
\text { LL: absent }\end{array}$ & $\begin{array}{l}\text { UL: NP } \\
\text { LL: normal }\end{array}$ & NP & - & + & $\begin{array}{l}\text { Brother with similar } \\
\text { symptoms (NA) }\end{array}$ \\
\hline 8 & $53, F$ & 70 & - & + & - & + & $\begin{array}{l}\text { UL: } \downarrow \\
\text { LL: absent }\end{array}$ & $\begin{array}{l}\text { UL: normal } \\
\text { LL: normal }\end{array}$ & $\begin{array}{l}\text { Bilateral } \\
\text { vestibular } \\
\text { areflexia }\end{array}$ & Dry mouth & - & - \\
\hline 9 & $56, \mathrm{M}$ & 66 & - & + & + & + & $\begin{array}{l}\text { UL: absent } \\
\text { LL: } \downarrow \text { absent }\end{array}$ & $\begin{array}{l}\text { UL: normal } \\
\text { LL: normal }\end{array}$ & $\begin{array}{l}\text { Bilateral } \\
\text { vestibular } \\
\text { areflexia }\end{array}$ & $\mathrm{OH}, \mathrm{I}, \mathrm{C}$ & + & $\begin{array}{l}\text { Brother with similar } \\
\text { symptoms }\end{array}$ \\
\hline
\end{tabular}

C, constipation; CMAP, compound muscle action potential; F, female; I, impotence; LL, lower limbs; M, male; NA, not available for evaluation; NP, not performed; OH, orthostatic hypotension; PT, patient ID; SNAP, sensory nerve action potential; $\mathrm{U}$, urinary dysfunction; $\mathrm{UL}$, upper limbs. 
sensory neuropathy, the diagnostic yield of RFC1 testing increased to $28.1 \%$ (9/32). If we only considered patients with ataxia onset after 35 years (similar to the cut-off for late-onset ataxia in a previous RFC1 study ${ }^{1}$ ), the yield was $12.7 \%(9 / 71)$. If we only included patients with onset after 35 years and both cerebellar ataxia and sensory neuropathy, the yield was $30.0 \%$ (9/30).

Three of the nine positive cases had a sibling with reportedly similar symptoms. One of these (brother of patient 9) was available for evaluation and was found to also have full CANVAS and a biallelic (AAGGG) exp $_{\text {in }}$ RFC1. His clinical features were described in a recent case report ${ }^{4}$ and he was not included in the determination of diagnostic yield, which was restricted to the 85 index patients.

Six of 85 patients (7.1\%) were heterozygous for (AAGGG) $)_{\exp }$, which is considered non-pathogenic carrier status. ${ }^{1}$ Three of them carried the reference (AAAAG) two the (AAAAG) $)_{\exp }$ and one the (AAAG$G)_{\exp }$ configuration on the other allele. The (AAGGG) $)_{\exp } /(\mathrm{AAAGG})_{\exp }$ carrier had ataxia onset at 58 years and sensory neuropathy.

Eight patients carried two repeat expansions of repeat units other than (AAGGG): biallelic (AAAAG) $)_{\exp }$ in four, biallelic $(\mathrm{AAAGG})_{\exp }$ in one and (AAAAG) $)_{\exp }$ ' (AAAGG) $)_{\exp }$ in three.

\section{DISCUSSION}

Biallelic (AAGGG) $)_{\exp }$ in RFC1 were a relatively frequent cause of adult-onset cerebellar ataxia in our cohort. Importantly, all nine positive cases also had a sensory or sensorimotor neuropathy, although this was subclinical in one. None had pure cerebellar ataxia with normal findings on NCS. Based on these data, we recommend performing NCS in all cases of unexplained adult-onset cerebellar ataxia to detect a subclinical or confirm a clinically suspected sensory neuropathy. If NCS shows sensory neuropathy, RFC1 testing is highly recommended. If NCS shows no sensory nerve impairment, RFC1 mutations seem very unlikely. Consistent with this, a recent description of 100 patients with biallelic RFC1 (AAGGG) exp $_{\text {identified }}$ sensory neuropathy as a common feature in all cases, while cerebellar ataxia was less frequent, leading the authors to suggest progression from sensory neuropathy early on to later cerebellar dysfunction. ${ }^{3}$

The frequency of positive cases in our adult-onset ataxia cohort was lower than in a London-based cohort, even if we used the same onset age cut-off of 35 years $(12.7 \%$ in our study vs $22 \%),{ }^{1}$ but was higher than recently reported for adultonset ataxia cohorts from Canada (4.3\%) and Brazil $(0.6 \%) .^{5}$ This may be due to differences in ethnic composition of the cohorts or different inclusion criteria for adult-onset ataxia.

We found one patient with cerebellar ataxia and subclinical sensory neuropathy and a (AAGGG) $)_{\exp } /(\mathrm{AAAGG})_{\exp }$ state. This constitution was previously reported in a CANVAS patient, ${ }^{2}$ but also in a healthy control. ${ }^{1}$ Although we cannot exclude that the (AAGGG) $)_{\exp } /(\mathrm{AAAGG})_{\exp }$ configuration might cause disease, evidence for its pathogenicity is currently insufficient. The (AAGGG) $)_{\exp } /(\mathrm{AAAAG})_{\exp }$ configuration is also considered non-pathogenic. ${ }^{1}$

Limitations of our study were the lack of vestibular investigations in six of nine cases, the retrospective nature of clinical descriptions and the fact that we did not determine exact repeat expansion lengths. Longitudinal studies of biallelic

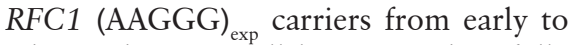
advanced stages will be required to fully characterise the clinical phenotype.

Sien Hilde Van Daele, ${ }^{1,2,3}$ Sascha Vermeer, ${ }^{4}$ Amélie Van Eesbeeck, ${ }^{4}$ Laura Lannoo, ${ }^{1}$ Valérie Race, ${ }^{4}$ Philip van Damme ${ }^{\circ}, 1,2,3$ Kristl Claeys, ${ }^{1,2}$ Wim Vandenberghe ${ }^{1,2}$

'Department of Neurology, University Hospitals Leuven, Leuven, Flanders, Belgium

${ }^{2}$ Department of Neurosciences and Leuven Brain Institute, KU Leuven, Leuven, Flanders, Belgium ${ }^{3}$ Center for Brain \& Disease Research, VIB, Leuven, Flanders, Belgium

${ }^{4}$ Center for Human Genetics, University Hospitals Leuven, Leuven, Flanders, Belgium

Correspondence to Professor Wim Vandenberghe, Department of Neurology, University Hospitals Leuven, Leuven 3000, Belgium; wim.vandenberghe@uzleuven. be

Acknowledgements We thank the patients participating in this study. KC and PvD hold the Emil von Behring Chair in Neuromuscular and Neurodegenerative Disorders by CSL Behring. Several authors of this publication are member of the
European Reference Network for Rare Neuromuscular Diseases (ERN Euro-NMD) and of the European Reference Network for Rare Neurological Diseases (ERN-RND).

Contributors Study concept and design: WV. Acquisition of data: SHVD, LL, WV and AVE. Analysis and interpretation of data: SHVD, SV, AVE and WV. Drafting the manuscript: SHVD and SV. Critical revision of the manuscript for important intellectual content: AVE, LL, VR, PvD, KC and WV.

Funding SHVD is funded by a PhD fellowship of the Research Foundation-Flanders (FWO) (1164018N,file number 40900). PvD and WV are Senior Clinical investigators of FWO. PVD is supportedby the ALS Liga België and the KU Leuven funds ' "Een Hart voor ALS', 'Laeversfonds voorALS Onderzoek' and the 'Valéry Perrier Race against ALS Fund'.

Competing interests None declared.

Patient consent for publication Not required.

Ethics approval The study was approved by the institutional Ethics Committee (approval number: S61184).

Provenance and peer review Not commissioned; externally peer reviewed.

(C) Author(s) (or their employer(s)) 2020. No commercial re-use. See rights and permissions. Published by BMJ.

\section{Check for updates}

To cite Van Daele SH, Vermeer S, Van Eesbeeck A, et al. I Neurol Neurosurg Psychiatry Epub ahead of print: [please include Day Month Year]. doi:10.1136/jnnp2020-323998

Received 25 May 2020

Revised 23 June 2020

Accepted 25 June 2020

J Neurol Neurosurg Psychiatry 2020;0:1-2. doi:10.1136/jnnp-2020-323998

\section{ORCID iDs}

Philip van Damme http://orcid.org/0000-0002-40102357

Wim Vandenberghe http://orcid.org/0000-0002-97585062

\section{REFERENCES}

1 Cortese A, Simone R, Sullivan R, et al. Biallelic expansion of an intronic repeat in RFC1 is a common cause of late-onset ataxia. Nat Genet 2019;51:649-58.

2 Rafehi H, Szmulewicz DJ, Bennett MF, et al.

Bioinformatics-Based identification of expanded repeats: a Non-reference intronic pentamer expansion in RFC1 causes CANVAS. Am J Hum Genet 2019;105:151-65.

3 Cortese A, Tozza S, Yau WY, et al. Cerebellar ataxia, neuropathy, vestibular areflexia syndrome due to RFC1 repeat expansion. Brain 2020;143:480-90.

4 Terryn J, Van Eesbeeck A, Vermeer S, et al. The characteristic eye movement disorder of RFC1-linked CANVAS. Mov Disord Clin Pract 2020;7:230-1.

5 Akçimen F, Ross JP, Bourassa CV, et al. Investigation of the RFC1 Repeat Expansion in a Canadian and a Brazilian Ataxia Cohort: Identification of Novel Conformations. Front Genet 2019;10:1219. 